\section{Not so elementary}

Introduction to Particle Production in Hadron Physics. By S. Humble. Pp. viii +253 . (Academic Press: London and New York, 1974.) £6.80; \$17.50.

THERE are some subjects that cannot be taught. One can only learn them by experiencing their harsh realities oneself. And one can only face such a task when driven by powerful motivation or attracted by the hint of great excitement to be found along the thorny path. Just such a subject is particle production in hadronic interactions.

That the author of this book has succeeded in producing a clear and balanced exposition of an incredibly difficult topic, is noteworthy. That he has failed to generate in us the necessary desire and excitement is a pity.

It is an unhappy, but surely not an unexpected fact, that as elementary particles are made to collide at ever higher energies, more and more debris of an increasingly complicated character is found to emerge from the collision. It is by studying this debris that we are supposed to be able to deduce the structure and the dynamical properties of the colliding particles. But what a daunting task. Even a description of the debris (that is, of the momenta and energies of the emerging particles) is too complicated to comprehend. How do you communicate to someone your findings concerning the dependence of a scattering amplitude upon the 14 variables needed to characterise a final state of 6 particles?

It is well nigh impossible, therefore, to hope to work back from data to dynamics. Rather, one postulates a dynamical model and attempts to confront it with the data.

There are several models currently in vogue, all interesting, none very convincing. The author attempts to describe and compare them fairly comprehensively. I found the discussion of dual models very informative, especially the treatment of their predictions and of the difficulties involved in their computation. The section on the analytical propenties of production amplitudes is particularly valuable, if only for the fact that it exposes the enormous complexity of the problems encountered. Multiperipheral and multiregge models are presented with a nice balance between essential fact and gory detail.

The text is marred by ugly typography (even an equation split between pages) and by many errors. I cannot refrain from seizing on the following sentence which most appropriately appears just below a typographical error: "Hence, it must always be a good idea in a practical calculation to derive as much of the formalism as one can for oneself, rather than relying on even the most detailed texts."

Other points to carp at: too little physical motivation for the ideas of 'scaling' in inclusive reactions; too much emphasis on the original work of Lurcat and Mazur on phase-space integrals, when more modern and simpler techniques exist; a lack of depth and a certain banality in summarising the properties of the models.

All said, however, this is a useful book. It is a good attempt to come to grips with an enormously difficult subject. Buit-and this must be stressedit is essentially a book for the would-be professional, and it demands more than a modicum of expertise in the theory of elementary particles.

E. Leader

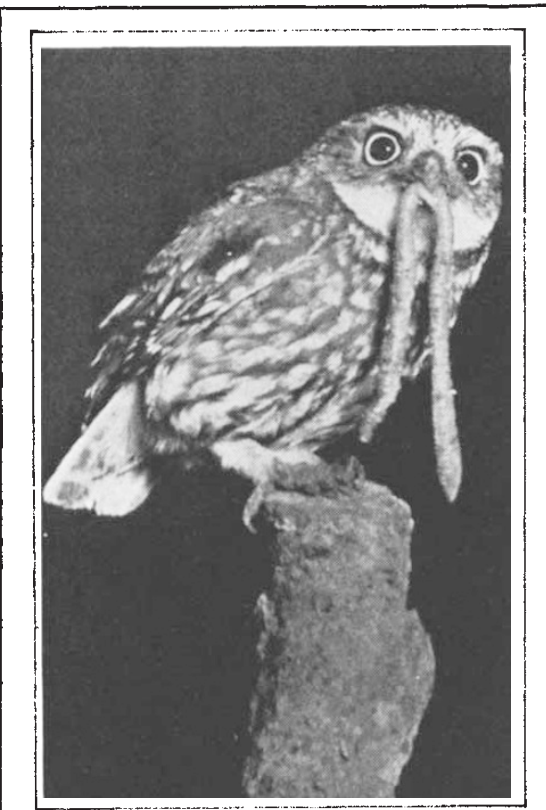

An early bird: the little owl, first introduced into Britain-where it is still relatively uncommon-during the last century. From Birds. By Christopher Perrins. Pp. 176. (Collins: London, September 1974.) f1.95. One of a series of books which also includes Woodlands, by William Condry, and Life on the Sea Shore, by John Barret.

\section{Encompassing the North Atlantic}

The Ocean Basins and Margins. (Vol. 2, The North Atlantic.) Edited by A. E. M. Nairn. Pp. xiv +598 . (Plenum Press: New York and London, 1974.) $\$ 45.60$.

THE North Atlantic must be among the most comprehensively surveyed ocean basins; and in order to arrive at a picture of its age and evolution it is necessary to consider not only the marine geophysical data amassed in recent years, but also a century or more of detailed geological research on the bordering continents. A few earth scientists are able to keep abreast of this vast volume of data. The rest of us, I imagine, tend to rely on the available reviews; and, ideally, these should be compiled in one authoritative and up-to-date volume covering every aspect of the problem. The fact that this second volume in the series The Ocean Basins and Margins comes close to realising the ideal should make it a much sought-after book.

Sins of omission are generally few, though chapters on the palaeomagnetic data from the North Atlantic continents and on sedimentation would have been welcome, and the northern reaches of the ocean deserve more attention. A general criticism which can be levelled at this volume, in its role as a source book, is that some chapters make reference to work published in 1973, whereas others, judging from their reference lists, were completed and on the editor's desk in 1971. There was surely ample time for the latter to be brought more up to date, if only by following the example given in $\mathrm{M}$. J. Keen's chapter, which includes an appendix of useful references published after the completion of the manuscript.

On the credit side, however, the book does cover much the greater part of what needs to be known about the North Atlantic. The editors set the scene in their opening chapter with a qualified acceptance of the 1972 Pitman and Talwani model for the evolution of the ocean basin. Stehli and Keen review the geology of the well known western margin (Bahamas to Newfoundland) and point out some of the problems which remain to be solved. Owen (Western Approaches to the British Isles), Vigneaux (Biscay) and Dillon and Sougy cover the eastern margins, the last of these authors contributing a particularly valuable summary of western African geology. The major oceanic islandsAzores (Ridley, Watkins and MacFarlane), Canaries and Cape Verde (Dillon and Sougy) and Iceland (Noe-Nygaard) -are all described, the last in a good review of the North Atlantic Cainozoic volcanism. Evidence for an older 'proto-Atlantic' is to be found in the Lower Palaeozoic orogenic belts of the northern Appalachians (Williams, Kennedy and Neale), southern Caledonides (Dewey), and Scandinavia (Nicholson). The account of the tectonics of Newfoundland and the summary of the British Caledonides are particularly good. Additional references to the Caledonian orogeny, and much useful data pertaining to the early history of the ocean basin of the present northern North Atlantic can be found in a clear 